\title{
The impact of obesity on health-related quality of life in Spain
}

\author{
Rafael Busutil ${ }^{1}$, Olga Espallardo ${ }^{1}$, Antonio Torres², Lucía Martínez-Galdeano ${ }^{3}$, Néboa Zozaya ${ }^{3^{*}}$ (D) \\ and Álvaro Hidalgo-Vega ${ }^{4}$
}

\begin{abstract}
Background: It is well documented that obesity is strongly associated with mortality and morbidity, but less is known about its impact on functional status and health-related quality of life (HRQOL). The purpose of this study was to calculate the impact of the Body Mass Index (BMI) on the HRQOL of the Spanish adult population, with special emphasis on $\mathrm{BMI} \geq 35$.
\end{abstract}

Methods: We used the Spanish National Health Survey (SNHS) 2011-2012 to assess the statistical association between $\mathrm{HRQOL}$, measured through the EuroQol-5D-5L questionnaire, and the BMI. We conducted linear regression analysis for the EuroQol-5D-5L Visual Analogue Scale (VAS) and probit regressions for each of the five dimensions of the EuroQol-5D-5L.

Results: Self-perceived problems in the five dimensions of the EuroQol-5D-5L increased along the BMl, especially in the mobility and pain/discomfort dimensions. Having a BMI $\geq 35$ reduced HRQOL even in the absence of chronic diseases. After controlling for comorbidities, severe obesity decreased the VAS score by an average of 1.9 points and increased the probability of reporting any HRQOL problem in mobility (11.8\%), self-care (2.2\%), usual activities (4.3\%) and pain/discomfort (7.4\%). No association was found between obesity and mental problems. All the parameters analysed suggest that HRQOL in women and people aged 65 years and over was significantly worse than average.

Conclusions: BMI is an explanatory factor of self-perceived quality of life. Obesity is associated with a worse HRQOL, especially in women and people aged over 64 years. These results may be useful for designing prevention or treatment health policies to target obesity among the Spanish population.

Keywords: BMl, Obesity, Quality of life, HRQOL, Spain

\section{Background}

Obesity has been described as the epidemic of the twentyfirst century [1,2], and has become a major problem of public health due to its high prevalence and impact on morbidity, mortality, quality of life and healthcare expenditure. In Spain, one in two adults aged 25-60 years has a Body Mass Index (BMI) above the recommendation $\left(B M I \geq 25 \mathrm{~kg} / \mathrm{m}^{2}\right)$ and $14.5 \%$ are obese $\left(\mathrm{BMI} \geq 30 \mathrm{~kg} / \mathrm{m}^{2}\right)$ [3]. These figures are expected to continue increasing $[4,5]$.

Comorbidities of obesity, mainly type II diabetes mellitus, cardiometabolic factors, cardiovascular diseases, asthma, certain cancers and musculoskeletal disorders, have been widely documented [6-9]. Obesity and its associated

* Correspondence: neboa.zozaya@weber.org.es

${ }^{3}$ Instituto Max Weber, c/ Norias 123, 28221 Majadahonda, Madrid, Spain

Full list of author information is available at the end of the article complications produce a significant deterioration in healthrelated quality of life (HRQOL) [10]. Various studies have demonstrated that an increase in BMI leads to a decrease in HRQOL, especially in regards to physical aspects and pain [11-14], even in the absence of any other chronic disease [15]. In addition, obese people are more likely to suffer from depression [16, 17] and mood disorders [18], and the probability of suffering from these conditions is higher if obesity develops at an early age [19].

Although it is understood that obesity deteriorates people's HRQOL, few studies have been conducted on this topic in Spain, and published literature mostly focuses on specific communities or subpopulations [20-23]. The purpose of this study was to calculate the impact of BMI on the HRQOL of the adult population of 
Spain, especially those suffering from severe to morbid obesity (BMI $\left.\geq 35 \mathrm{~kg} / \mathrm{m}^{2}\right)$.

\section{Methods \\ Sample}

Microdata from the Spanish National Health Survey (SNHS), conducted in 2011-2012, were used as the main source of this analysis. SNHS is a longitudinal populationbased survey nationally representative, which includes a total of 26,502 interviews with adults and minors [24]. After excluding individuals with no available data to calculate BMI values and those aged under 18 years old, the analysed sample comprised 18,682 adult subjects, that is representative of the adult population of Spain.

\section{Body mass index}

BMI was calculated using data on self-reported weight and height, and individuals were classified according to the BMI cut-off points established by the World Health Organization (WHO) [6]. Additionally, since patients with a BMI greater than 35 and serious coexisting conditions, or that exceeds 40 , are potential candidates for bariatric surgery [25], obesity group was divided into two groups. According to this, the sample was classified as follows: underweight (BMI < 18.5), normal weight $(18.5 \leq \mathrm{BMI}<25)$, overweight $(25 \leq \mathrm{BMI}<30)$, moderate obesity, named obesity-A for this study $(30 \leq \mathrm{BMI}<35)$, and severe to morbid obesity, named obesity-B (BMI $\geq 35$ ). Obesity was subdivided in two groups (obesity-A and obesity-B) in order to be able to analyse if there was a gradual effect of obesity on quality of life, maintaining at the same time the statistical representability of the sample.

\section{Health-related quality of life}

The SNHS 2011-2012 includes the EuroQol-5D-5L (EQ-5D-5L) questionnaire [26], a standardised instrument of HRQOL that provides both a descriptive profile (5 dimensions: mobility, self-care, usual activities, pain/ discomfort, and anxiety/depression, each with 5 levels of response according to intensity) and a vertical visual analogue scale (VAS) that records the person's self-perceived state of health. Validated Spanish country-specific tariffs were used to convert each response combination into Quality Adjusted Life Years (QALYs), by assigning them a utility value which ranged between 0 (equivalent to death) and 1 (perfect health) [27]. The VAS scale ranges from 0 to 100 , representing the worst and best imaginable health states, respectively.

The SNHS also includes the Goldberg General Health Questionnaire (GHQ-12) [28], which detects the inability to carry out normal functions of a healthy person and the appearance of new and distressing phenomena, allowing us to analyse the mental health of the sample.

\section{Sociodemographic characteristics and comorbidities}

We included in the analysis those sociodemographic variables (age, gender, nationality, social class, marital status and region of residence [24]), self-reported lifestyle habits, and diagnosed chronic conditions (comorbidities) included in the SNHS that, according to the literature, might be associated with a higher BMI $[3,6-8,29]$. Comorbidities include respiratory diseases (asthma, chronic bronchitis, and COPD), cardiovascular diseases (heart attack, embolism and other heart diseases), muscular diseases (osteoarthritis and lower or upper back pain), stomach diseases (stomach ulcer), diabetes, anxiety and chronic depression, other mental diseases, tumours, migraines, problems with the prostate, thyroid or skin, allergy, urinary incontinence, cataracts, cirrhosis and risk factors (cholesterol and high blood pressure).

\section{Statistical analysis}

Overall, 42 subjects who reported VAS values that contradicted utility values in the EQ-5D-5L were excluded from the analysis [utility $>0.8$ and VAS $<20(n=29)$; utility $<0.2$ and VAS $>80(n=13)]$.

Linear regression models (Ordinary Least Squares) were used to study the association between VAS values and obesity. Following a progressive inclusion rationale, we ran four different models, all of them controlled by age group and gender: Model 1 additionally controlled for socioeconomic characteristics and BMI; Model 2 controlled for socioeconomic variables, BMI, lifestyle and region of residence; Model 3 controlled for socioeconomic variables, BMI and diagnosed chronic conditions associated with obesity; and Model 4 controlled for socioeconomic variables, BMI, diagnosed chronic conditions, lifestyle and region of residence. Robust unstandardized regression coefficients were estimated.

Additionally, five independent probit regression models were performed, one for each of the 5 health dimensions of the EQ-5D-5L, in order to analyse the impact of obesity on mobility, self-care, usual activities, pain/discomfort and anxiety/depression. The purpose of the probit models is to estimate the probability that an observation with particular characteristics will fall into a specific category. The dependent variables took a value of ' 1 ' if any problem was reported in that particular dimension, and ' 0 ' if no problem was reported. We also tested the effects by age group ( $<65$ and $\geq 65$ years of age) and gender in separate models.

All explanatory variables took a categorical form (dummy), using as many values as the number of categories in each variable minus one (which would be the reference or comparison category). For instance, BMI was included in the models as four explanatory variables, with "normal weight" being the reference category.

A separate probit regression model was also performed to test the potential relationship between mental 
health and the BMI, controlling for covariates. GHQ-12 was the dependent variable, taking a value of ' 1 ' if any mental problem was reported and '0' if no mental problem was reported.

Statistical analysis was performed using SPSS 22 and Stata 11.0 software. A $p$-value of $<0.05$ was deemed significant.

\section{Results}

More than half of the Spanish adult population had a BMI that exceeded the WHO recommendation: 37.3\% were overweight, $13.3 \%$ were moderately obese (obesityA) and $3.9 \%$ were severely to morbidly obese (obesity-B).

The distribution of the QALYs and the VAS scores resultant from the EQ-5D-5L are shown in Fig. 1. The QALYs' histogram presents a J-shaped form, as $61.9 \%$ of the individuals in the sample reported not having any kind of problems in any of the five dimensions (1 QALY per year assuming that their utility remained constant during the whole year). In contrast, the VAS scores showed a more homogeneous distribution, with only $6.4 \%$ reporting a score of 100 , and $22.5 \%$ reporting a score of 90 or more.

People with normal weight reported a better selfperceived HRQOL than the rest of the sample (Table 1). HRQOL decreased as BMI increased, with obesity-B detracting 0.133 yearly QALYs to normal weight. Mean QALY scores for normal weight people stood for 0.9436, while these figures decreased to 0.9249 among people with overweight, 0.873 for obesity-A and 0.810 for obesity-B.

There were some gender differences. Women reported a lower HRQOL than men in all BMI categories, except for underweight. Obesity seemed to have a greater effect on HRQOL among women. On average, in comparison with respective normal weight groups, women with obesity-
B lost 0.185 QALYs per year versus 0.063 for men. QALYs also decreased as age increased, especially with higher BMIs: compared to normal weighted people, those with obesity-B aged under 44 years lost 0.046 QALYs per year, but the loss is 0.100 and 0.195 QALYs for people aged $45-64$ years and 65 years and over, respectively.

The analysis of the dimensions of the EQ-5D-5L showed that the frequency of reporting problems in all five dimensions increased with BMI. Overall, $92.3 \%$ of respondents with normal weight reported no problems with mobility, while this percentage dropped by 25.5 points in respondents with $\mathrm{BMI} \geq 35$. This trend was maintained in the rest of the dimensions (Fig. 2). The largest proportion of problems was found in the pain/ discomfort dimension, where only $56 \%$ of subjects with obesity-B reported having no pain and $12.5 \%$ reported severe or extreme pain.

Problems in all dimensions increased in the subsample of respondents aged 65 years and over. Among these subjects, obesity-B increased mobility problems by $36.3 \%$, self-care problems by $20.2 \%$, usual activities by $28.4 \%$ and pain/discomfort by $31.4 \%$ compared to normal weight peers.

\section{Regression models}

The results from the linear regression models showed that BMI is an explanatory factor of the self-perceived state of health (VAS score), independently of the variables used as control (Table 2). Compared to normal weight, a higher BMI progressively worsened VAS scores. The reductive effects of BMI on VAS got smaller when controlling by chronic diseases (models 3 and 4), as would be expected. In model 4 , compared to normal weight, obesity$\mathrm{A}$ and obesity-B reduced the VAS score by an average of 1.9 points $(p<0.001)$ and 3.7 points $(p<0.001)$, respectively. These effects more than double in the simplified

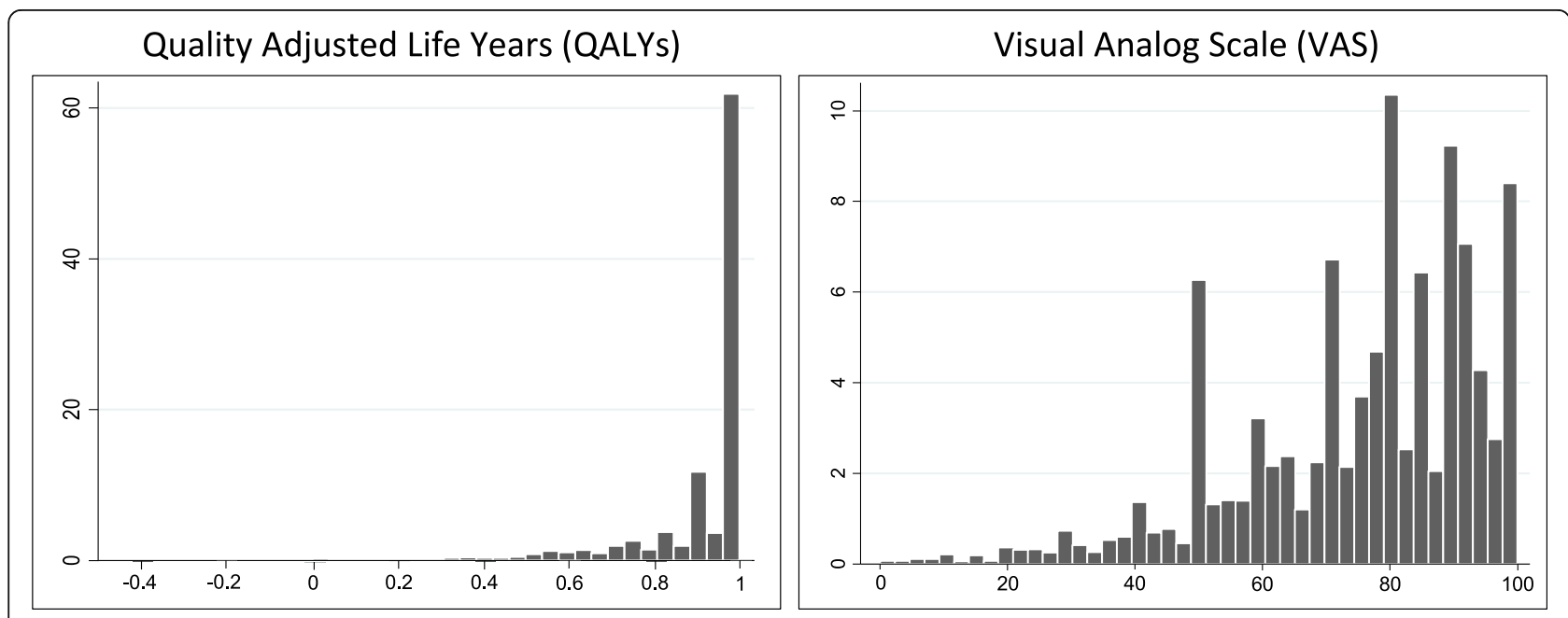

Fig. 1 Distribution histograms of QALYS and VAS scores derived from the SNHS 
Table 1 Quality-adjusted life years (QALYs) per year, by sex and age group, according to BMl

\begin{tabular}{|c|c|c|c|c|c|}
\hline & Underweight & Normal weight & Overweight & Obesity-A & Obesity-B \\
\hline Total & 0.923 & 0.943 & 0.925 & 0.873 & 0.810 \\
\hline \multicolumn{6}{|l|}{ Sex } \\
\hline Man & 0.893 & 0.956 & 0.947 & 0.911 & 0.893 \\
\hline Woman & 0.932 & 0.934 & 0.890 & 0.825 & 0.749 \\
\hline \multicolumn{6}{|l|}{ Age (years) } \\
\hline$\leq 44$ & 0.966 & 0.972 & 0.972 & 0.951 & 0.926 \\
\hline $45-64$ & 0.866 & 0.926 & 0.931 & 0.902 & 0.826 \\
\hline$\geq 65$ & 0.640 & 0.827 & 0.831 & 0.743 & 0.632 \\
\hline
\end{tabular}

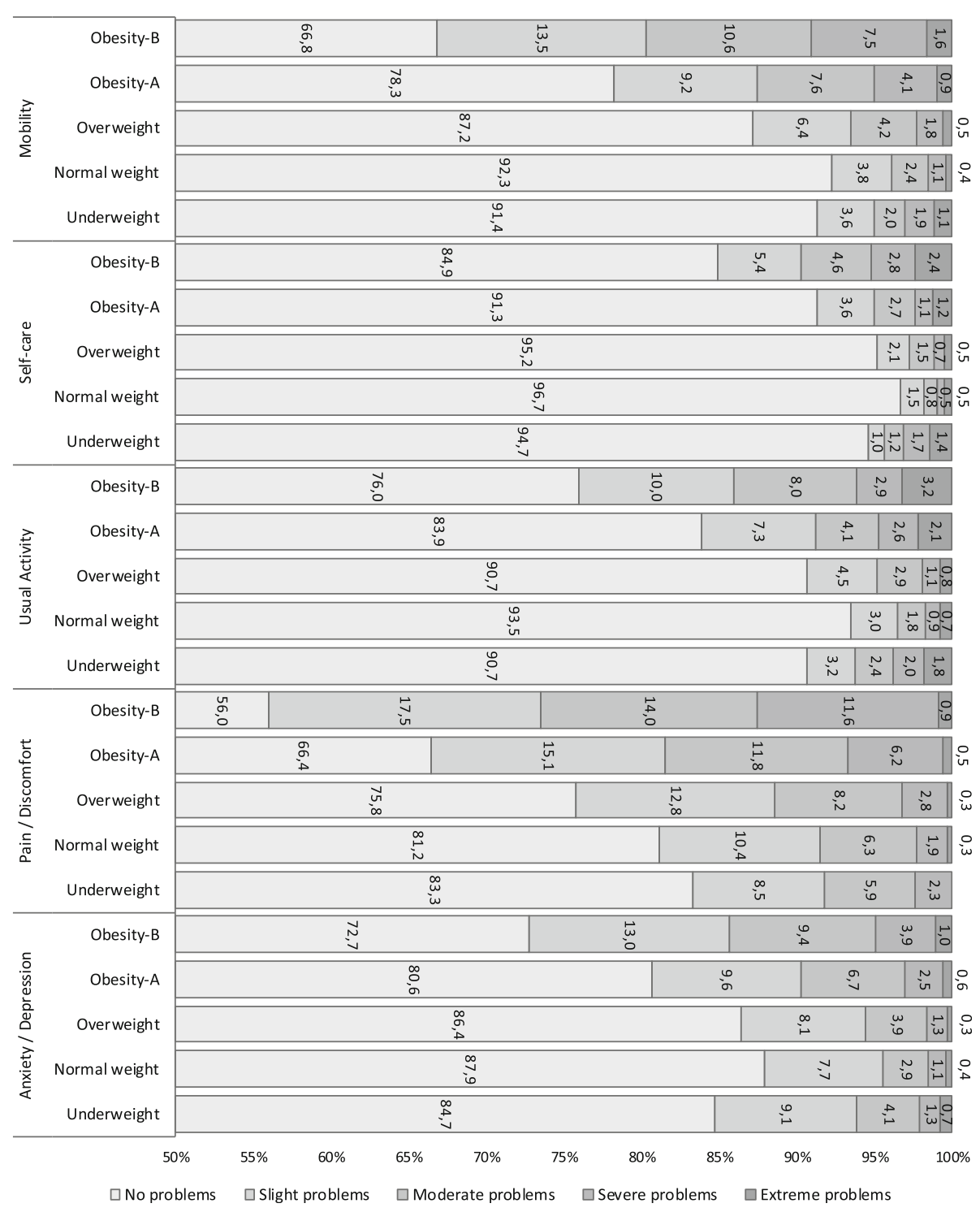

Fig. 2 Prevalence of self-reported problems at the five dimensions of the EQ-5D-5L, according to BMI 
Table 2 Results from the four linear regression models (unstandardized regression coefficients estimated by Ordinary Least Squares)

\begin{tabular}{|c|c|c|c|c|}
\hline & Dependen & og Scale (VA & score $0-10$ & \\
\hline & Model 1 & Model 2 & Model 3 & Model 4 \\
\hline Man & $2.67^{* * *}$ & $2.40^{* * *}$ & $0.53^{*}$ & 0.37 \\
\hline 45-64 years old & $-7.40^{* * *}$ & $-7.26^{* * *}$ & $-3.89 * * *$ & $-3.79^{* * *}$ \\
\hline$\geq 65$ years old & $-14.84^{* * *}$ & $-15.47^{* * *}$ & $-7.26^{* * *}$ & $-7.69^{* * *}$ \\
\hline Upper class & $2.55^{* * *}$ & $2.32^{* * *}$ & $1.57^{* * *}$ & $1.40^{* * *}$ \\
\hline Lower class & $-1.45^{* * *}$ & $-1.38^{* * *}$ & $-0.78^{*}$ & $-0.78^{*}$ \\
\hline Foreign & $3.60^{* * *}$ & $3.30^{* * *}$ & $2.04^{* * *}$ & $1.83^{* * *}$ \\
\hline Married & -0.44 & -0.29 & -0.03 & 0.08 \\
\hline Separated & $-2.12^{* * *}$ & $-1.95^{* * *}$ & -0.65 & -0.50 \\
\hline Widowed & $-4.54^{* * *}$ & $-4.67^{* * *}$ & $-2.02^{* * *}$ & $-2.12^{* * *}$ \\
\hline Underweight & $-2.20^{*}$ & $-2.13^{*}$ & $-2.62^{* *}$ & $-2.55^{* *}$ \\
\hline Overweight & $-1.83^{* * *}$ & $-1.67^{* * *}$ & $-0.72^{* *}$ & $-0.61^{*}$ \\
\hline Obesity-A & $-4.82^{* * *}$ & $-4.57^{* * *}$ & $-2.06^{* * *}$ & $-1.92^{* * *}$ \\
\hline Obesity-B & $-9.30^{* * *}$ & $-8.91^{* * *}$ & $-3.92^{* * *}$ & $-3.70^{* * *}$ \\
\hline Northern region & & -0.31 & & -0.35 \\
\hline Southern region & & 1.06 & & 0.62 \\
\hline Western region & & $1.71^{* * *}$ & & $1.17^{* * *}$ \\
\hline Eastern region & & -0.65 & & -0.46 \\
\hline Smoking & & $-1.29 * * *$ & & $-0.85^{* *}$ \\
\hline Alcohol consumption & & $-4.70^{* * *}$ & & $-4.13^{* * *}$ \\
\hline Physical exercise & & -0.47 & & $-0.75^{*}$ \\
\hline Respiratory diseases & & & $-3.65^{* * *}$ & $-3.58^{* * *}$ \\
\hline Vascular diseases & & & $-7.82^{* * *}$ & $-7.76^{* * *}$ \\
\hline Muscular diseases & & & $-7.34^{* * *}$ & $-7.35^{* * *}$ \\
\hline Stomach diseases & & & $-3.57^{* * *}$ & $-3.49^{* * *}$ \\
\hline Diabetes & & & $-4.67^{* * *}$ & $-4.73^{* * *}$ \\
\hline Depression/anxiety & & & $-9.53^{* * *}$ & $-9.32^{* * *}$ \\
\hline Risk factors & & & $-2.52^{* * *}$ & $-2.53^{* * *}$ \\
\hline Other diseases & & & $-3.94^{* * *}$ & $-3.97^{* * *}$ \\
\hline Constant & $83.55^{* * *}$ & $83.96^{* * *}$ & $87.90^{* * *}$ & $88.41^{* * *}$ \\
\hline $\mathrm{n}$ & 18,516 & 18,516 & 18,332 & 18,332 \\
\hline$R^{2}$ & 0.189 & 0.197 & 0.339 & 0.344 \\
\hline Adjusted $R^{2}$ & 0.1884 & 0.1960 & 0.3381 & 0.3432 \\
\hline
\end{tabular}

Model 1: Socioeconomic variables + BMl; Model 2: Socioeconomic variables + BMI + Lifestyle + Region of residence; Model 3: Socioeconomic variables + $\mathrm{BMI}+$ Chronic diseases; Model 4: Socioeconomic variables + BMI + Chronic diseases + Lifestyle + Region of residence. The models include robust standardized errors

${ }^{*} p<0.05,{ }^{* *} p<0.01,{ }^{* * *} p<0.001$

The reference values were the following: woman (for gender), aged under 45 years old (for age group), middle class (for social class), Spanish (for nationality), single (for marital status), no diagnosed chronic disease (for each comorbidity), no smoker, no risky drinker, sedentarism (for lifestyle habits), normal weight (for $\mathrm{BMI}$ ) and central region (for region of residence)

Description of the independent variables: Social class (Upper: university graduate or director/manager of company; Middle: self-employed person or skilled worker; Lower: semi-skilled or unskilled worker or primary sector worker). Region of residence (Central region: the Community of Madrid, Castilla-La Mancha and Castilla León; Northern region: Navarre, the Basque Country, Aragon and la Rioja; Southern region: Andalusia, Extremadura, Murcia, the Canary Islands, Ceuta and Melilla; Western region: Galicia, Asturias and Cantabria; Eastern region: Catalonia, the Valencian Community and the Balearic Islands). Lifestyle habits (smoking dairy or occasionally; being a risky drinker: drinking more than 35 alcohol units during the past week, if male, or more than 25 alcohol units, if female; physical exercise: walking at least $20 \mathrm{~min}$ in the past week). Diagnosed diseases (Respiratory diseases: asthma, chronic bronchitis and COPD; Cardiovascular diseases: heart attack, embolism and other heart diseases; Muscular diseases: osteoarthritis and lower or upper back pain; Stomach diseases: stomach ulcer; diabetes; depression/anxiety: anxiety and chronic depression; risk factors: cholesterol and high blood pressure; other diseases: other mental diseases, tumours, migraines, problems with the prostate, thyroid or skin, allergy, urinary incontinence, cataracts and cirrhosis) 
models (model 1 and 2), and were also statistically significant. According to the adjusted R-squared values derived from the prediction models, the independent variables explained up to $34 \%$ of the total variability of self-perceived quality of life, indicating a fairly good fit.
The results of the probit models for each of the EQ-5D5L dimensions showed how BMI affects each dimension differently (Table 3). Compared to normal weight, obesity-B significantly affects mobility, self-care, usual activities and pain/discomfort, increasing the probability of reporting

Table 3 Results from the probit regression models (marginal effects) for each of the EQ-5D-5L dimensions for the sample as a whole

\begin{tabular}{|c|c|c|c|c|c|}
\hline & DIM1: Mobility & DIM2: Self-care & DIM3: Usual Activities & DIM4: Pain/Discomfort & DIM5: Anxiety/Depression \\
\hline Man & -0.0007 & -0.0023 & -0.0063 & $-0.0609^{* *}$ & $-0.0301^{* *}$ \\
\hline 45-64 years old & $0.0748^{* *}$ & $0.0219^{* *}$ & $0.0351^{* *}$ & $0.0559^{* *}$ & $0.0364^{* *}$ \\
\hline$\geq 65$ years old & $0.2350^{* *}$ & $0.0855^{* *}$ & $0.1196^{* *}$ & $0.1203^{* *}$ & $0.0240^{*}$ \\
\hline Upper class & $-0.0246^{* *}$ & $-0.0079^{*}$ & $-0.0167^{* *}$ & $-0.0453^{* *}$ & -0.0076 \\
\hline Lower class & 0.0065 & $0.0076^{*}$ & $0.0117^{*}$ & 0.0168 & $0.0212^{*}$ \\
\hline Foreign & -0.0078 & -0.0063 & $-0.0161^{*}$ & 0.0002 & $0.0267^{*}$ \\
\hline Married & $-0.0158^{*}$ & -0.0052 & -0.0056 & 0.0063 & -0.0061 \\
\hline Separated & -0.0139 & 0.0020 & -0.0007 & -0.0001 & 0.0200 \\
\hline Widowed & $0.0259^{*}$ & $0.0149^{*}$ & $0.0311^{* *}$ & $0.0329^{*}$ & $0.0403^{*}$ \\
\hline Respiratory diseases & $0.0314^{* *}$ & 0.0057 & $0.0255^{* *}$ & $0.0539^{* *}$ & 0.0169 \\
\hline Vascular diseases & $0.0924^{* *}$ & $0.0398^{* *}$ & $0.0856^{* *}$ & $0.1010^{* *}$ & $0.0523^{* *}$ \\
\hline Muscular diseases & $0.1109^{* *}$ & $0.0334^{* *}$ & $0.0815^{* *}$ & $0.3027^{* *}$ & $0.0481^{* *}$ \\
\hline Stomach diseases & $0.0272^{*}$ & 0.0017 & 0.0065 & $0.0532^{*}$ & 0.0224 \\
\hline Diabetes & $0.0602^{* *}$ & $0.0170^{* *}$ & $0.0413^{* *}$ & $0.0549^{* *}$ & 0.0122 \\
\hline Depression/anxiety & $0.0701^{* *}$ & $0.0253^{* *}$ & $0.0764^{* *}$ & $0.1522^{* *}$ & $0.5364^{* *}$ \\
\hline Risk factors & 0.0032 & -0.0005 & 0.0022 & $0.0461^{* *}$ & $0.0247^{* *}$ \\
\hline Other diseases & $0.0472^{* *}$ & $0.0188^{* *}$ & $0.0509^{* *}$ & $0.0779^{* *}$ & $0.0301^{* *}$ \\
\hline Smoking & 0.0071 & -0.0028 & -0.0001 & 0.0024 & $0.0261^{* *}$ \\
\hline Alcohol consumption & 0.0045 & $-0.0118^{*}$ & -0.0120 & 0.0156 & -0.0086 \\
\hline Physical exercise & -0.0088 & 0.0002 & $-0.0114^{*}$ & $-0.0150^{*}$ & $-0.0123^{*}$ \\
\hline Underweight & 0.0289 & $0.0326^{*}$ & $0.0501^{*}$ & 0.0297 & 0.0383 \\
\hline Overweight & 0.0066 & -0.0040 & -0.0051 & 0.0041 & -0.0068 \\
\hline Obesity-A & $0.0334^{* *}$ & 0.0013 & 0.0101 & $0.0366^{*}$ & 0.0085 \\
\hline Obesity-B & $0.1182^{* *}$ & $0.0217^{*}$ & $0.0427^{* *}$ & $0.0743^{* *}$ & 0.0199 \\
\hline Northern region & $-0.0172^{*}$ & 0.0004 & $0.0128^{*}$ & $-0.0319^{*}$ & -0.0134 \\
\hline Southern region & $0.0239^{* *}$ & $0.0127^{* *}$ & $0.0337^{* *}$ & -0.0017 & 0.0105 \\
\hline Western region & $0.0172^{*}$ & $0.0111^{*}$ & $0.0304^{* *}$ & -0.0182 & $0.0190^{*}$ \\
\hline Eastern region & $0.0141^{*}$ & 0.0059 & $0.0278^{* *}$ & $0.0262^{*}$ & $0.0338^{* *}$ \\
\hline$n$ & 18,444 & 18,444 & 18,443 & 18,438 & 18,433 \\
\hline Pseudo $R^{2}$ & 0.319 & 0.284 & 0.301 & 0.259 & 0.309 \\
\hline
\end{tabular}

Probabilities of developing a problem

* $p<0.05$ *** $p<0.001$

The reference values were the following: woman (for gender), aged under 45 years old (for age group), middle class (for social class), Spanish (for nationality), single (for marital status), no diagnosed chronic disease (for each comorbidity), no smoker, no risky drinker, sedentarism (for lifestyle habits), normal weight (for $\mathrm{BMI}$ ) and central region (for region of residence)

Description of the independent variables: Social class (Upper: university graduate or director/manager of company; Middle: self-employed person or skilled worker; Lower: semi-skilled or unskilled worker or primary sector worker). Diagnosed diseases (Respiratory diseases: asthma, chronic bronchitis and COPD; Cardiovascular diseases: heart attack, embolism and other heart diseases; Muscular diseases: osteoarthritis and lower or upper back pain; Stomach diseases: stomach ulcer; diabetes; depression/anxiety: anxiety and chronic depression; risk factors: cholesterol and high blood pressure; other diseases: other mental diseases, tumours, migraines, problems with the prostate, thyroid or skin, allergy, urinary incontinence, cataracts and cirrhosis). Lifestyle habits (smoking dairy or occasionally; being a risky drinker: drinking more than 35 alcohol units during the past week, if male, or more than 25 alcohol units, if female; physical exercise: walking at least 20 min in the past week). Region of residence (Central region: the Community of Madrid, Castilla-La Mancha and Castilla León; Northern region: Navarre, the Basque Country, Aragon and la Rioja; Southern region: Andalusia, Extremadura, Murcia, the Canary Islands, Ceuta and Melilla; Western region: Galicia, Asturias and Cantabria; Eastern region: Catalonia, the Valencian Community and the Balearic Islands) 
problems at these dimensions by $11.8 \%, 2.2 \%, 4.3 \%$ and $7.4 \%$, respectively. However, obesity-B did not have a significant effect on the likelihood of reporting depression/ anxiety problems.

Table 4 reveals the results after distinguishing by age and gender. In the full sample, mobility was the dimension most affected by obesity, followed by pain/discomfort. When separated models by age groups were analyzed, the probability of reporting any problem at any EQ-5D-5L dimension was significantly higher in the obese $\geq 65$ age group (both genders) when compared to normal weight old people. In this group, the probability of reporting any mobility problems increased from $3.3 \%$ to $9.5 \%$ with obesity-A and from $11.8 \%$ to $18 \%$ with obesity-B. In people under 65 , the associated probabilities drop to $2 \%$ and $9.3 \%$, respectively.

The results by gender show that the only dimension that is significantly likely to be affected by obesity in men is mobility, both in the sample comprising "all ages" and in the sample of younger men. By contrast, women of both age groups with obesity-B were more likely to report problems in all dimensions but anxiety/depression, compared to women with normal weight. Regardless of their age, obesity-B in women increased by $16 \%$ the probability of declaring mobility problems compared to $6 \%$ in men. This probability rose to $23 \%$ in women aged over 65 years. In women under 65 , obesity-B increased the probability of reporting problems related to mobility, self-care, usual activities and pain by $12.1 \%, 2.3 \%, 3.7 \%$ and $11.3 \%$, respectively, compared to women with normal weight. These values rose to $23.3 \%, 12.4 \%, 19.7 \%$ and $13.7 \%$, respectively, for women aged 65 years or over. The pseudo R-squared values derived from the probit models indicated a fairly goodness-of-fit, with better predictions of the outcome for the general population than for subsets.

The results of the model using the GHQ-12 scores as the dependent value (not reported in tables) were consistent with the results obtained for the depression/ anxiety dimension of the EQ-5D-5L. There was no statistically significant association between BMI and mental health ( $p=0.606$ for obesity-A and $p=0.842$ for obesity-B).

\section{Discussion}

Obesity is related to the development of comorbidities that impair not only the person's objective health status but also their self-perceived health. In this study we have confirmed, through different econometric models, that obesity is a determining factor of a worse HRQOL, whether the latter is measured using a linear thermometer (VAS scores) or through the reporting of problems in the five dimensions of the EQ-5D-5L. The EQ-5D is a generic instrument (the only HRQOL instrument included in the SNHS) for measuring HRQOL, that is widely used for economic evaluation in many areas of health research.

Both the Visual Analogue Scale and the EQ-5D-5L descriptive system conform the EuroQol, but they measure conceptually different aspects of self-perceived health. They are highly correlated (Spearman test coefficient: 0.587; $p=0.00$ ), but their distributions showed substantial differences (Fig. 1), which could be partially attributed to the following factors. The 'end-point aversion' is a measurement bias that occurs when people are not likely to use the extreme ends of the scales [30]. Health states perceived as worse than death do not have a proper representation on the VAS, unlike the EQ-5D-5L index, which allows for disutilities in extremely severe health states. Besides, as a direct measure of selfperceived health status, the VAS is more subject to the patient's interpretation and subjectivity than QALY scores. We tried to control this problem by dismissing outliers from the analysis.

To our knowledge, this is the first study that analyses the effects of BMI on HRQOL using the EQ-5D-5L questionnaire, which is more precise than its previous version (EQ-5D-3L) comprising only three possible problem level answers.

Our results show that the greater the excessive BMI, the higher the probability of having a low self-perceived health status, regardless of age and gender. According to our findings, moderate obesity and severe-to-morbid obesity reduced self-perceived health status by approximately 2 and 4 points, respectively, after controlling for diagnosed chronic diseases.

With respect to the EQ-5D-5L dimensions, obesity-B primarily affected mobility and pain/discomfort, and to a lesser extent usual activities and self-care. However, obesity did not appear to be associated with depression or anxiety problems. This is consistent with the analysis conducted on the GHQ-12, that suggested that there was no significant association between obesity and mental health.

Women systematically reported a lower HRQOL than men. This trend was exacerbated by the deeper negative effect of obesity on women's self-perceived quality of life. Among people aged 65 years and over, obesity-B was statistically associated with lower HRQOL. This association was stronger than that in people under 65 years. Women were particularly affected by this age effect.

Our results are consistent with the published empirical literature. Among other studies conducted in Spain, Serrano-Aguilar et al. found that obesity in the Canary Islands had a significant negative impact on HRQOL, even in people who did not suffer from chronic diseases. The authors showed that people with $\mathrm{BMI} \geq 25$ had a higher probability of indicating a worse HRQOL, and 


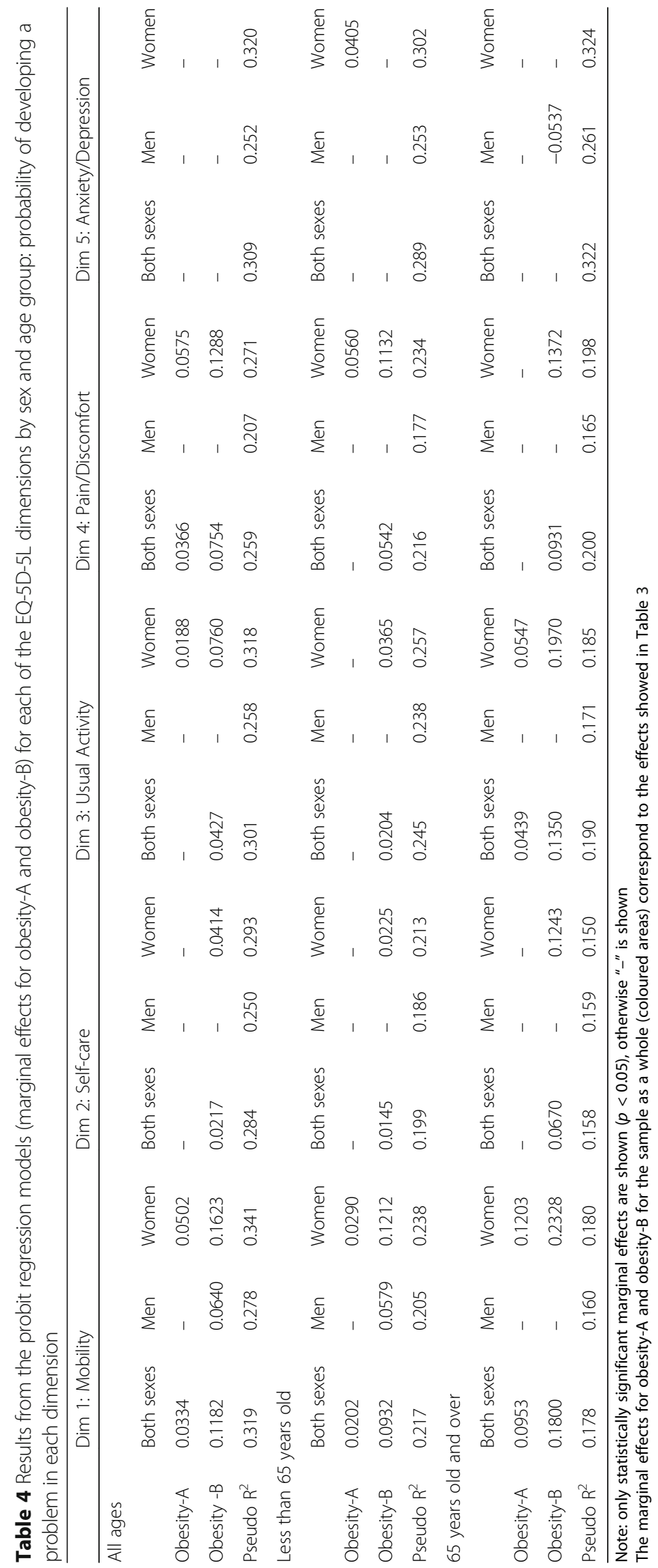


that the effect was greater in women than in men. People with class II obesity $(35 \leq$ BMI $<40)$ had a $47 \%$ higher probability of reporting a worse HRQOL, while people with class III obesity (BMI $\geq 40$ ) were 3 times more likely to have a worse HRQOL than people with normal weight [22]. Similarly, Oliva-Moreno et al. found that the effects of severe to morbid obesity were greater than those of moderate obesity, that excess weight significantly diminished self-perceived health status, and that this effect was stronger in women than in men. In their study, where the EuroQol questionnaire with 3 levels was used, the most affected dimension by obesity was also mobility, followed by pain/discomfort, in line with our results [23].

At worldwide level, some studies have corroborated the significant and negative association between BMI and self-perceived quality of life, measuring the latter with different instruments such as the EQ-5D-3L or the Short-Form 36 (SF-36) [9, 11-15, 31-36]. Most of these studies confirmed that the malignant effect of obesity is greater in women than in men and that obesity is linked to a worse physical HRQOL, but there is no consensus on the mental HRQOL component.

It is well stated that women self-report worse HRQOL than men [37]. This gap is largely explained by sociodemographic and socioeconomic status differentials between men and women, but there are other factors that may be relevant, such as differential reporting patterns. In elderly women, the difference seems to be mainly due to a higher prevalence of disability and chronic conditions [38].

While obesity is a well-recognized risk factor for impaired HRQOL, few studies have investigated the underlying biological mechanisms of this relationship. The effects of obesity on obesity-related diseases and self-reported health are expected to be involved in the mechanisms underlying the obesity-HRQOL association. Some authors argued that the long-term physiological effects of obesity are numerous and potentiate each other [39]. Park et al. explored the potential causal pathways and mediating effects of the pathologic conditions that may explain this association and the difference among gender groups [36]. The study concluded that obesity was only directly associated with HRQOL in women. In men, it was indirectly associated with HRQOL through diabetes mellitus, hypertension, dyslipidemia and self-rated health. Psychological differences between genders, such as dissatisfaction with body shapes, weight selfstigmatization, internalization of weight bias and higher perceived health risk associated with obesity could account for this disease-independent pathway.

The relationship between obesity and mental health has been subject of considerable debate. Alike the present study, several reviews and individual studies were inconclusive in relation to the influence of obesity on mental
HRQOL, reporting no or very weak association [40-42]. However, a recent meta-analysis concluded that both mental and physical quality of life were impaired in class III obese individuals (BMI $\geq 40$ ), although it founded no statistically significant association for less obese people [34]. Some biological studies indicated that stress, anxiety and depression could be the cause of obesity and that a two-way causal relationship may exist [43]. Poor emotional well-being among the obese may be due to comorbidity rather than obesity per se [44]. Generic measures of HRQOL might not be sensitive enough to reflect impairment in mental HRQOL, especially among those with less severe obesity.

Our results are not free from limitations. First, the SNHS provides self-reported HRQOL measured at a specific moment in time, which does not enable us to analyse the evolution over time or the causality between obesity and lower self-perceived HRQOL. Some longitudinal studies studied the evolution of this relationship over time $[45,46]$. Second, in the SNHS, HRQOL was measured through self-reported questionnaires, thus providing a subjective value, dependent on the relative perception of the person at that specific point of time. In addition, BMI is derived from self-reported data of height and weight. If, as previous studies suggested, people tend to underestimate their weight and to overestimate their height, our results may be underestimating the real prevalence of obesity in the sample [17, 47-49]. To conclude, some studies argue that BMI is not a valid measurement of obesity for people older than 65 [50]. Therefore, our results for this populations' segment should be interpreted with caution.

Our results could serve as a basis for designing and implementing health policies. Over the last decades, interventions to address the growing obesity epidemic have escalated [39]. Available modalities for the treatment of adult obesity include clinical counselling focused on diet and physical activity, pharmacotherapy, and bariatric surgery $[51,52]$. Because the prevalence of obesity poses an enormous clinical burden, innovative treatment strategies are needed, whose success will depend on taking into account relevant cultural, economic and social aspects. Decision makers should have access to key sources of data on the burdens associated with obesity, such as reduced life expectancy and lower health-related quality of life, in order to build sound policies focused on reducing the negative effects of obesity on today's society.

\section{Conclusions}

Overweight and obesity affect more than half of the Spanish adult population. We showed that obesity is associated with a worse health-related quality of life, especially in women and people over the age of 65. A BMI over 35 appears to be prejudicial for mobility and discomfort, 
affecting daily activities, but we found no connexion between obesity and mental problems such as anxiety or depression. Despite the limitations of our study, we can confirm that the data from the SNHS 2011-2012 provide new and valid information on the impact of obesity on people's self-perceived HRQOL, as well as on the different ways in which it affects people according to their gender and age group. This information may be useful for designing prevention and treatment health policies that target obesity among the Spanish population.

\section{Abbreviations}

BMI: Body Mass Index; COPD: Chronic Obstructive Pulmonary Disease; EQ-5D3L: EuroQol-5D-3L; EQ-5D-5L: EuroQol-5D-5L; GHQ-12: Goldberg General Health Questionnaire; HRQOL: Health-Related Quality of Life; QALYs: Quality Adjusted Life Years; SNHS: Spanish National Health Survey; VAS: Visual Analogue Scale; WHO: World Health Organization

\section{Acknowledgements}

The authors are thankful to Juan Oliva Moreno, teacher at the University of Castilla-La Mancha, for his useful comments and suggestions regarding the design and interpretation of the statistical analysis performed at this study.

\section{Funding}

This study was supported by funding from Johnson \& Johnson Spain. The sponsor defined the objective of the study, but it didn't have any role in the analysis and interpretation of data and in the writing of the manuscript.

\section{Availability of data and materials}

For this article we used microdata from the Spanish National Health Survey, which is publicly available at the webpage of the Spanish Instituto Nacional de Estadística (http://www.ine.es).

The utility value scores applied to obtain the Spanish QALYs are publicly available at the EuroQol webpage (http://www.euroqol.org).

\section{Authors' contributions}

$\mathrm{RB}$ and $\mathrm{OE}$ conceived of the study and helped to draft the manuscript. LMG and NZ performed the statistical analysis and helped to draft the manuscript. AT and AHV helped to draft the manuscript. All authors read and approved the final manuscript.

\section{Authors' information}

Not applicable

\section{Ethics approval and consent to participate}

Not applicable

\section{Consent for publication}

Not applicable

\section{Competing interests}

The authors declare that they have no competing interests.

\section{Publisher's Note}

Springer Nature remains neutral with regard to jurisdictional claims in published maps and institutional affiliations.

\section{Author details}

${ }^{1}$ Seminario de Investigación en Economía y Salud, University of Castilla-La Mancha, Toledo, Spain. ${ }^{2}$ Hospital Clínico San Carlos, Madrid, Spain. ${ }^{3}$ Instituto Max Weber, c/ Norias 123, 28221 Majadahonda, Madrid, Spain. ${ }^{4}$ University of Castilla-La Mancha, Toledo, Spain.
Received: 21 April 2017 Accepted: 28 September 2017

Published online: 10 October 2017

\section{References}

1. WHO. Diet, nutrition and the prevention of chronic diseases. World Health Organ Tech Rep Ser. 2003;916:i-viii, 1-149.

2. James PT, Rigby N, Leach R, International Obesity Task Force. The obesity epidemic, metabolic syndrome and future prevention strategies. Eur $J$ Cardiovasc Prev Rehabil. Off. J. Eur. Soc. Cardiol. Work. Groups Epidemiol. Prev. Card. Rehabil. Exerc. Physiol 2004;11:3-8.

3. Aranceta-Bartrina J, Serra-Majem L, Foz-Sala M, Moreno-Esteban B, SEEDO GC. Prevalence of obesity in Spain. Med Clin Barc. 2005;125:460-6.

4. Rodríguez Artalejo F, López García E, Gutiérrez-Fisac JL, Banegas Banegas JR, Lafuente Urdinguio PJ, Domínguez Rojas V. Changes in the prevalence of overweight and obesity and their risk factors in Spain, 1987-1997. Prev Med. 2002;34:72-81.

5. Costa-Font J, Gil J. Obesity and the incidence of chronic diseases in Spain: a seemingly unrelated probit approach. Econ Hum Biol. 2005;3:188-214.

6. WHO. Obesity: preventing and managing the global epidemic. Report of a WHO consultation. World Health Organ Tech Rep Ser. 2000:894:i-xii, 1-253.

7. Guh DP, Zhang W, Bansback N, Amarsi Z, Birmingham CL, Anis AH. The incidence of co-morbidities related to obesity and overweight: a systematic review and meta-analysis. BMC Public Health. 2009;9:88.

8. Haslam DW, James WPT. Obesity. Lancet Lond Engl. 2005:366:1197-209.

9. Audureau E, Pouchot J, Coste J. Gender-Related Differential Effects of Obesity on Health-Related Quality of Life via Obesity-Related Comorbidities. Circ Cardiovasc Qual Outcomes. 2016;9(3):246-256. CIRCOUTCOMES-115.

10. Mar J, Karlsson J, Arrospide A, Mar B, Martínez de Aragón G, MartinezBlazquez C. Two-year changes in generic and obesity-specific quality of life after gastric bypass. Eat. Weight Disord. - Stud. Anorex. Bulim. Obes. 2013;18: $305-10$

11. Yancy WS Jr, Olsen MK, Westman EC, Bosworth HB, Edelman D. Relationship between obesity and health-related quality of life in men. Obes Res 2002;10: 1057-1064.

12. Huang IC, Frangakis $C$, AW W. The relationship of excess body weight and health-related quality of life: evidence from a population study in Taiwan. Int J Obes. 2006:30:1250-9.

13. Katz DA, McHorney CA, Atkinson RL. Impact of obesity on health-related quality of life in patients with chronic illness. J Gen Intern Med. 2000;15: 789-96.

14. Kortt MA, Clarke PM. Estimating utility values for health states of overweight and obese individuals using the SF-36. Qual Life Res. 2005;14:2177-85.

15. Jia H, Lubetkin El. The impact of obesity on health-related quality-of-life in the general adult US population. J Public Health Oxf. 2005;27:156-64.

16. Stunkard AJ, Faith MS, Allison KC. Depression and obesity. Biol Psychiatry. 2003:54:330-7.

17. Jarolimova J, Tagoni J, Stern TA. Obesity: its epidemiology, comorbidities, and management. Prim Care Companion CNS Disord [Internet]. 2013;15. Available from: http://www.ncbi.nlm.nih.gov/pubmed/24511434

18. Amianto F, Lavagnino L, Leombruni P, Gastaldi F, Daga GA, Fassino S. Hypomania across the binge eating spectrum. A study on hypomanic symptoms in full criteria and sub-threshold binge eating subjects. J Affect Disord. 2011;133:580-3.

19. Mustillo S, Worthman C, Erkanli A, Keeler G, Angold A, Costello EJ. Obesity and psychiatric disorder: developmental trajectories. Pediatrics. 2003;111: $851-9$

20. López-García E, Banegas Banegas JR, Gutiérrez-Fisac JL, Pérez-Regadera AG, Ganan LD, Rodríguez-Artalejo F. Relation between body weight and healthrelated quality of life among the elderly in Spain. Int J Obes Relat Metab Disord. 2003;27:701-9.

21. García-Mendizábal MJ, Carrasco JM, Pérez-Gómez B, Aragonés N, GuallarCastillón P, Rodríguez-Artalejo F, et al. Role of educational level in the relationship between Body Mass Index (BMI) and health-related quality of life (HRQL) among rural Spanish women. BMC Public Health. 2009;9:120.

22. Serrano-Aguilar P, Muñoz-Navarro SR, Ramallo-Fariña Y, Trujillo-Martín MM. Obesity and health related quality of life in the general adult population of the Canary Islands. Qual Life Res. Int. J. Qual. Life Asp. Treat. Care Rehabil. 2009;18:171-177.

23. Oliva-Moreno J, Gil-Lacruz A. Body weight and health-related quality of life in Catalonia, Spain. Eur J Health Econ. 2013;14:95-105. 
24. Instituto Nacionald de Estadística. Encuesta Nacional de Salud 2011-2012: Metodología [Internet]. Available from: http://www.ine.es/metodologia/t15/ t153041912.pdf

25. Consensus Development Conference Panel. Gastrointestinal Surgery for Severe Obesity. NIH conference. Ann Intern Med. 1991;115(12):956-61.

26. EuroQol Group. EuroQol-a new facility for the measurement of healthrelated quality of life. Health Policy Amst Neth. 1990;16:199-208.

27. van Reenen, M, Janssen, B. EQ-5D-5L User Guide. Basic information on to use the EQ-5D-5L instrument. 2015; Available from: https://euroqol.org/wp content/uploads/2016/09/EQ-5D-5L_UserGuide_2015.pdf

28. Sánchez-López Mdel P, Dresch V. The 12-Item General Health Questionnaire (GHQ-12): reliability, external validity and factor structure in the Spanish population. Psicothema. 2008;20:839-43.

29. Marqueta de Salas M, Martín-Ramiro JJ, Juárez Soto JJ. Características sociodemográficas como factores de riesgo para la obesidad y el sobrepeso en la población adulta española. Med. Clínica. 2016;146:471-7.

30. Mozzi A, Meregaglia M, Lazzaro C, Tornatore V, Belfiglio M, Fattore G. A comparison of EuroQol 5-Dimension health-related utilities using Italian, UK, and US preference weights in a patient sample. Clin Outcomes Res CEOR. 2016;8:267-74.

31. Kearns K, Dee A, Fitzgerald AP, Doherty E, Perry IJ. Chronic disease burden associated with overweight and obesity in Ireland: the effects of a small BMI reduction at population level. BMC Public Health. 2014;14:143.

32. Kearns B, Ara R, Young T, Relton C. Association between body mass index and health-related quality of life, and the impact of self-reported long-term conditions - cross-sectional study from the south Yorkshire cohort dataset. BMC Public Health. 2013;13:1009.

33. McLaughlin L, Hinyard LJ. The Relationship Between Health-Related Quality of Life and Body Mass Index. West J Nurs Res. 2014;36:989-1001.

34. UI-Haq Z, Mackay DF, Fenwick E, Pell JP. Meta-analysis of the association between body mass index and health-related quality of life among adults, assessed by the SF-36. Obesity. 2013;21:E322-7.

35. Cullinan J, Gillespie P. Does Overweight and Obesity Impact on SelfRated Health? Evidence Using Instrumental Variables Ordered Probit Models. Health Econ. [Internet]. 2015 [cited 2015 Oct 26]; Available from: http://onlinelibrary.wiley.com/doi/10.1002/hec.3215/abstract

36. Park S. Pathways linking obesity to health-related quality of life. Qual Life Res. 2017;26:2209-18.

37. Cherepanov D, Palta M, Fryback DG, Robert SA. Gender differences in health-related quality-of-life are partly explained by sociodemographic and socioeconomic variation between adult men and women in the US: evidence from four US nationally representative data sets. Qual Life Res. 2010;19:1115-24

38. Orfila F, Ferrer M, Lamarca R, Tebe C, Domingo-Salvany A, Alonso J. Gender differences in health-related quality of life among the elderly: The role of objective functional capacity and chronic conditions. Soc Sci Med. 2006;63: 2367-80.

39. Williams EP, Mesidor M, Winters K, Dubbert PM, Wyatt SB. Overweight and Obesity: Prevalence, Consequences, and Causes of a Growing Public Health Problem. Curr Obes Rep. 2015;4:363-70.

40. Hopman WM, Berger C, Joseph L, Barr SI, Gao Y, Prior JC, et al. The association between body mass index and health-related quality of life: data from CaMos, a stratified population study. Qual Life Res Int J Qual Life Asp Treat Care Rehabil. 2007:16:1595-603.

41. de Zwaan M, Petersen I, Kaerber M, Burgmer R, Nolting B, Legenbauer T, et al. Obesity and quality of life: a controlled study of normal-weight and obese individuals. Psychosomatics. 2009;50:474-82.

42. Fontaine KR, Barofsky I. Obesity and health-related quality of life. Obes Rev. 2001;2:173-82

43. Muennig P, Lubetkin E, Jia H, Franks P. Gender and the burden of disease attributable to obesity. Am J Public Health. 2006;96:1662-8.

44. Doll HA, Petersen SE, Stewart-Brown SL. Obesity and physical and emotional well-being: associations between body mass index, chronic illness, and the physical and mental components of the SF-36 questionnaire. Obes Res. 2000:8:160-70

45. Stafford M, Hemingway $H$, Marmot M. Current obesity, steady weight change and weight fluctuation as predictors of physical functioning in middle aged office workers: the Whitehall II Study. Int J Obes Relat Metab Disord. J. Int. Assoc. Study Obes. 1998;22:23-31.

46. Muller-Nordhorn J, Muckelbauer R, Englert H, Grittner U, Berger H, Sonntag F, et al. Longitudinal Association between Body Mass Index and HealthRelated Quality of Life. PLoS One. 2014;9:e93071.
47. Kuczmarski MF, Kuczmarski RJ, Najjar M. Effects of age on validity of selfreported height, weight, and body mass index: findings from the Third National Health and Nutrition Examination Survey, 1988-1994. J Am Diet Assoc. 2001;101:28-34. quiz 35-6

48. Spencer EA, Appleby PN, Davey GK, Key TJ. Validity of self-reported height and weight in 4808 EPIC-Oxford participants. Public Health Nutr. 2002:5:561-5.

49. Gil J, Mora T. The determinants of misreporting weight and height: The role of social norms. Econ Hum Biol. 2011;9:78-91.

50. Winter JE, Maclnnis RJ, Wattanapenpaiboon N, Nowson CABMI. all-cause mortality in older adults: a meta-analysis. Am J Clin Nutr. 2014;99:875-91.

51. Dietz WH, Baur LA, Hall K, Puhl RM, Taveras EM, Uauy R, et al. Management of obesity: improvement of health-care training and systems for prevention and care. Lancet. 2015;385:2521-33.

52. Huang TT-K, Cawley JH, Ashe M, Costa SA, Frerichs LM, Zwicker L, et al. Mobilisation of public support for policy actions to prevent obesity. Lancet. 2015;385:2422-31.

\section{Submit your next manuscript to BioMed Central and we will help you at every step:}

- We accept pre-submission inquiries

- Our selector tool helps you to find the most relevant journal

- We provide round the clock customer support

- Convenient online submission

- Thorough peer review

- Inclusion in PubMed and all major indexing services

- Maximum visibility for your research

Submit your manuscript at www.biomedcentral.com/submit
) Biomed Central 